\title{
Behavioral and psychological symptoms in dementia and caregiver burden
}

\author{
Arshad Yahya, Mina Chandra*, Kuljeet Singh Anand, Jyoti Garg \\ Department of Neurology, PGIMER and Dr Ram Manohar Lohia Hospital, New Delhi, India
}

Email address:

minasaxena@gmail.com (M. Chandra)

To cite this article:

Arshad Yahya, Mina Chandra, Kuljit Singh Anand, Jyoti Garg. Behavioral and Psychological Symptoms in Dementia and Caregiver Burden. Clinical Medicine Research. Special Issue: Recent Research in Dementia. Vol. 4, No. 2-1, 2015, pp. 8-14.

doi: 10.11648/j.cmr.s.2015040201.12

\begin{abstract}
Dementia is a mental health disorder of global public health concern. The syndrome of dementia may be caused by various underlying diseases, each characterized by a specific constellation of signs and symptoms in combination with a presumed underlying substrate of neuropathology. Behavioral and psychological symptoms are integral part of dementia. They increase morbidity, influence quality of life and are major source of care giver burden. To be effective, dementia care need to focus on the early detection of BPSD and its management. The spectrum of behavioral and psychological symptoms in different each types of dementia are different and they should be managed accordingly to relieve care giver burden.
\end{abstract}

Keywords: Dementia, Alzheimer's Disease, BPSD, Caregiver, Burden, Vascular Dementia, DLB, FTD, PDD

\section{Introduction}

Dementia is defined as a considerable decline in cognitive functions that is severe enough to impair the ability to perform personal activities of daily living. Dementia may involve memory impairment, decline in socio-occupational functioning, impaired executive function, speech deficits, personality changes, and behavioral and psychological disturbances. The syndrome of dementia may be caused by various underlying diseases, each characterized by a specific constellation of signs and symptoms in combination with a presumed underlying substrate of neuropathology. Alzheimer's disease (AD) is the most common sub-type of dementia with, approximately two-third of dementia cases over 65 years being diagnosed as AD. The other subtype of dementia includes vascular dementia or multi-infarct dementia (MID), Lewy body dementia (DLB), Parkinson's disease Dementia (PDD), Fronto temporal dementia. ${ }^{1}$ Behavioral and psychological symptoms are integral part of dementia. They increase morbidity, influence quality of life and are major source of care giver burden. ${ }^{2}$

\subsection{Epidemiology of Dementia and BPSD}

The World Health Organization (WHO) predicts that by 2025 , about $75 \%$ of the estimated 1.2 billion people aged 60 years and older will reside in developing countries . ${ }^{3}$ In 2005, it was estimated that more than 24 million people globally and nearly 2 million people in India are affected with dementia. 4

As per Das et al, rate of growth will be the highest (around $336 \%$ ) in India, China, South Asia, and western Pacific regions, 235-393\% in Latin America and Africa, and the lowest $(100 \%)$ in developed regions. ${ }^{5}$.

In India the number of people with Alzheimer's disease and other dementias is increasing every year because of the steady growth in the older population and stable increment in life expectancy. It is estimated that 4.6 million incident or new cases are added yearly such that the number of people living with dementia will almost double every 20 years to 42.3 million in 2020 and 81.1 million in $2040 .^{5}$. Prevalence of dementia was higher in women than in men and nearly doubled with every five year increase in age. ${ }^{6}$

BPSD symptoms are 4 times more common in patients with dementia than older adults without dementia ${ }^{7}$. The prevalence of BPSD in community is estimated to be about $20 \%{ }^{7,8}$. The prevalence of behavioral symptoms is greater in nursing homes than in community settings ${ }^{9}$ The prevalence of BPSD in the 24 hour care settings has been reported to be as high as $90 \%$,by some studies with individual behaviors including delusions (20\%-73\%), depression (up to $80 \%$ ), and aggression and hostility $(20 \%-50 \%)$. Nearly $60 \%$ of the patients presenting to a memory clinic in one study showed 
behavioral disturbances, with psychotic and activityassociated disturbances being the most common presentations. ${ }^{10}$

It has been suggested that BPSD can exhibit variations across different cultures Preliminary studies of BPSD from India have reported high prevalence rates comparable to most western studies, with caregivers reporting these symptoms as the most distressing and difficult to manage. ${ }^{11}$

\subsection{Evolution of the Concept of BPSD}

Alois Alzheimer initial description of dementia includes behavioral and psychological symptoms of dementia (BPSD) as prominent manifestations of the illness, including paranoia, delusions of sexual abuse, hallucinations and screaming. ${ }^{12}$. In 1996, the International Psycho Geriatric Association convened a consensus conference on the behavioral disturbances in dementia. The consensus group made the statement: "The term behavioral disturbances should be replaced by the term BPSD, defined as symptoms of disturbed perception, thought content, mood or behavior that frequently occur in patients with dementia. ${ }^{13}$ The BPSD symptoms are listed in Table 1 . These broadly conform to BPSD symptoms as described in Cummings' Neuropsychiatric Inventory ${ }^{14}$.
Table 1. Spectrum of $B P S D$

\begin{tabular}{ll}
\hline Behavioral Symptoms & Psychological Symptoms \\
\hline $\begin{array}{l}\text { Usually identified on the basis of } \\
\text { observation of the patient. They } \\
\text { include the following: }\end{array}$ & $\begin{array}{l}\text { Usually and mainly assessed on the } \\
\text { basis of mental status examination of } \\
\text { patient and interviews with } \\
\text { caregivers. They include the } \\
\text { following: } \\
\text { Mood disturbances like depressed } \\
\text { mousive behavior, physical }\end{array}$ \\
$\begin{array}{ll}\text { aggression and screaming } \\
\text { emotional lability and anxiety } \\
\text { wandering }\end{array}$ & $\begin{array}{l}\text { Delusions especially of persecution, } \\
\text { reference, misidentification } \\
\text { (including Capgras Syndrome). }\end{array}$ \\
Culturally inappropriate behavior, & $\begin{array}{l}\text { Hallucinations- auditory, visual, } \\
\text { tactile and tactile }\end{array}$ \\
Sexual disinhibition, & Apathy, amotivation \\
Hoarding, searching, & Sleep disturbances \\
Following and shadowing. & Changes in appetite
\end{tabular}

\subsubsection{Categorical Vs Dimensional Approach}

While individual symptoms as described above form the categorical approach to BPSD, several authors have found clustering of symptoms which may reflect underlying dimensions. Factor Analysis using NPI have revealed similar set of dimensions in different studies (Table 2) confirming that BPSD is not a homogeneous entity and is best understood as a constellation of dimensions.

Table 2. Dimensional approaches to BPSD

\begin{tabular}{|c|c|c|c|c|c|c|}
\hline Author & Dimensions & & & & & \\
\hline Frisoni et al 1999 & Mood & & Psychosis & & & $\begin{array}{l}\text { Frontal lobe } \\
\text { sx }\end{array}$ \\
\hline Fuh et al 2001 & Mood- Psychosis & & & & $\begin{array}{l}\text { Psychomotor } \\
\text { regulation }\end{array}$ & $\begin{array}{l}\text { Social } \\
\text { engagement }\end{array}$ \\
\hline Aalten et al 2003 & Mood- apathy & & Psychosis & & Hyper activity & - \\
\hline Benoit et al 2003 & Mood & & Hallucination & & Psychosis- Agitation & - \\
\hline Spalletta 2004 & $\begin{array}{l}\text { Mood } \\
\text { depression- } \\
\text { apathy }\end{array}$ & $\begin{array}{l}\text { Mood excite- } \\
\text { ment }\end{array}$ & Psychosis & & Hyperactivity & - \\
\hline Mirakhur 2004 & Affect & Mania & Psychosis & & Physical & - \\
\hline Matsui 2006 & Mood & Euphoria & Psychosis & & & - \\
\hline Chen & Depression- apathy & $\begin{array}{l}\text { Euphoria- } \\
\text { disinhibition }\end{array}$ & $\begin{array}{l}\text { Halluciantion- } \\
\text { time behavior }\end{array}$ & Night & Agitation Aggression -Delusion & Appetite \\
\hline
\end{tabular}

BPSD is not a diagnostic entity but is instead a term that describes a clinical dimension of dementia.

BPSD can cause tremendous distress for both the patient and the caregiver, and is often the trigger for referral of these patients to primary care and specialist services and placement in residential or nursing home care. ${ }^{15}$ The development of BPSD is also associated with a poorer prognosis, a more rapid rate of cognitive decline, illness progression, greater impairment in activities of daily living (ADLs) and diminished quality of life (QOL)), and it adds significantly to the direct and indirect costs of care. ${ }^{16}$

\subsubsection{Nosological Status}

BPSD have not been accorded any diagnostic status in current classificatory systems including ICD-10, DSM 5,
NINDS ARDRA, NINDS AIREN etc which focus exclusively on cognitive symptoms, functional decline and neurological signs.

ICD 10 allows BPSD to be coded as a specifier (predominantly delusional, predominantly hallucinatory, predominantly depressive and othermixed symptoms) with a severity sub specifier. ${ }^{17}$

DSM 5 does allow BPSD to be coded as a behavioral disturbance specifier with sub specifiers of psychotic disorder, mood disorder, anxiety disorder, personality change and sleep disturbance which capture most but not all BPSD symptoms. It also does not accord it any diagnostic or prognostic significance. The issue of psychiatric symptoms versus psychiatric syndrome versus disorder has also not been clarified for BPSD in the context of dementia ${ }^{18}$. 


\subsection{Natural History and Course of BPSD}

BPSD symptoms usually fluctuate over the course of dementia. ${ }^{19,20}$

\subsubsection{Early Stage Dementia Vs Late Stage}

Depressive symptoms often occur in the early stages of dementia. As dementia progresses, other behavioral and psychological symptoms may predominate. Increased cognitive impairment was associated with more activity disturbances, hallucinations, agitation and sleep disturbances; however, delusions, affective disturbances, anxieties and phobias improved with worsening of the cognitive status. Only circadian rhythm disturbances were significantly associated with worsening cognitive status. ${ }^{10}$

Kar et al mentioned the association of BPSD with mini mental status examination score (MMSE). In his study, he reported BPSD in $92.5 \%$ of patients with MMSE between $11-20$ and $84 \%$ of patients with MMSE $21-30 .^{21}$

\subsubsection{Persistence Rates}

A study of patients with mild AD found that wandering and purposeless/inappropriate activities persisted or increased in severity over 2 years in about $85 \%$ of patients who had these symptoms at baseline, while paranoid ideation persisted in approximately $66 \%$ of patients. ${ }^{22}$ Hallucinations and depressive symptoms were the least persistent symptoms: less than half of the patients with depressive symptoms still had the symptoms one year later.

\subsection{BPSD and Type of Dementia}

Different Dementias show typical clustering of BPSD (vide table 3). As emergence of BPSD symptoms may precede cognitive decline in a substantial number of cases ${ }^{23}$, such clustering of BPSD symptoms should raise high index of suspicion in clinical practice. However since most symptoms are not specific to a dementia subtype, identification of dementia subtype is often possible only after emergence of cognitive and motor symptoms.

Table 3. BPSD in different Dementias

\begin{tabular}{lll}
\hline Dementia & Common BPSD & Less common BPSD \\
\hline Alzheimer's Disease & Apathy, agitation, wandering, depression, anxiety & $\begin{array}{l}\text { Delusions, hallucinations, aberrant sexual } \\
\text { behavior }\end{array}$ \\
& Delusions, visual hallucinations, REM sleep & Other hallucinations \\
Dementia with Lewy Bodies & Depression, Anxiety, Delusions, hallucinations, & Obsessive- Compulsive symptoms, aberrant \\
& REM sleep behavioral disorder & sexual behavior \\
Parkinson's Disease & Apathy, Disinhibition, Dietary changes & Disinhibition \\
Fronto- Temporal Dementia & Apathy & Apathy \\
Progressive Supra nuclear Palsy & Depression & \\
Cortico-Basal Degeneration & &
\end{tabular}

As many as $80 \%$ of Alzheimer's dementia (AD) patients will develop symptoms of BPSD during the course of their illness, often with the onset of cognitive impairment. ${ }^{7}$ Zaudig found that patients with mixed $\mathrm{AD}$ and vascular dementia have the highest level of psychiatric disturbances. ${ }^{21}$

Type specific BPSD,e.g; hallucination for DLB, activity disturbances like apathy for FTD, anxiety and phobia for AD and affective disturbances for $\mathrm{VaD}$ have been identified ${ }^{91}$ in multiple studies. ${ }^{24}$

\subsubsection{Psychotic Symptoms}

Approximately $30-50 \%$ of AD patients have been reported to have delusions and hallucinations ${ }^{21}$ in one study. Cummings et al. (1987) suggested that the frequency of persecutory delusions in multi-infarct dementia (MID) is greater than in $\mathrm{AD} .{ }^{25}$ The frequency of delusion varies between $10 \%$ and $73 \%$. ${ }^{26}$ The most common delusions in demented people are persecutory or paranoid. ${ }^{27}$ Paranoid delusions in $\mathrm{AD}$ have been interpreted as an adaptive response to the cognitive deterioration and the patients' decreasing ability to grasp and appropriately interpret reality.

${ }^{10}$ Other common delusions include Delusion of reference and misidentification including Capgras Syndrome.

Cummings et al. (1987) noted a higher frequency of hallucinations in patients with $\mathrm{AD}^{25}$ while Berrios and Brook (1985) found it comparable in all dementias 28.
Hallucinations should be differentiated from visual agnosia and misidentification due to poor vision. The frequency of hallucinations in dementia ranges from $12 \%$ to $49 \%$. ${ }^{29}$ Visual hallucinations are the most common occurring in up to $30 \%$ of patients, and these are more common in moderate dementia. ${ }^{27}$ In people with Lewy bodies, the frequency can be as high as $80 \%$. ${ }^{30}$ Even in AD, Visual hallucinations are more common than auditory. ${ }^{31}$

Several authors have suggested that unlike Functional Psychosis delusions and hallucination in dementia may be part of different subsyndromes. ${ }^{32,33}$ Further, unlike delusions, hallucinations are associated with more severe cognitive impairment. ${ }^{34}$

\subsubsection{Irritabilty and Aggression}

A study concludes that Aggression and activity disturbances are among the most commonly seen BPSD, and it has been suggested that patients with $\mathrm{AD}$ have a higher frequency of aggression. ${ }^{10}$

Physical violence and hitting occurs in approximately $30 \%$ of AD. ${ }^{35}$ Premorbid aggressions are predictor of aggressive behavior in dementia. ${ }^{21}$

\subsubsection{Mood Disturbances}

Prevalence rates of depression across various types of dementia are controversial, with some investigators reporting a higher frequency of depression in $\mathrm{AD}$ compared to other 
types, and others reporting the contrary. ${ }^{36}$ Depression in patients with dementia stems from neurotransmitter dysfunction associated with the underlying disease process and also from the patients' recognition of the severity of their cognitive impairment. ${ }^{37}$ The sudden loss of abilities in VaD can result in an increased incidence of anxiety in the patients.

${ }^{38}$ In a study, depressed mood occurs in $40-50 \%$ of patients of dementia. ${ }^{36}$

\subsubsection{Apathy}

Apathy is present in up to $50 \%$ of patients in the early and intermediate stages of $\mathrm{AD}$ and other dementias. Apathy may manifest lack of interest in daily activities, self care, social interaction, lack of motivation and initiative and decreased range of affective expression and may be misdiagnosed as major depression. Although lack of motivation occurs in apathy and depression, in apathy amotivation occurs without concomitant dysphoria or vegetative symptoms and is the most common BPSD across all dementia ranges from $75-87 \%$ 39

\subsection{Etiopathological Mechanisms in BPSD}

While the origin of BPSD remains unclear; it is presumed there are multiple etiologies for these symptoms. There are neurobiological, psychological (premorbid personality features and responses to stress), and social (environmental change and caregiver factors) aspects in the development of BPSD. The neurobiology of behavioral disturbances involves correlations between memory deficits and decreasing cholinergic function; and between serotonin and noradrenaline depletion and a history of depression or aggression.

There is convincing evidence that the BPSD in AD has identifiable anatomical and biochemical etiological basis. Given the wide array of psychopathologic symptoms in AD, however, it is unlikely that lesions of specific brain structure are related with a specific BPSD.

\subsubsection{Neuroanatomical Correlates}

As can be expected, different behavioral problems reflect involvement of different cerebral areas. It has been shown that people with $\mathrm{AD}$ who develop psychosis have a 2.3-fold greater Density of NFT (neurofibrillary tangle) in the neocortex (middle frontal, anterior third of the superior temporal, inferior parietal) compared to $\mathrm{AD}$ patients who will not develop psychosis ${ }^{40}$.

Brain functional imaging studies have shown that psychosis in probable $\mathrm{AD}$ is associated with a reduction in prefrontal, left frontal-temporal, and right parietal metabolism ${ }^{41-42}$.Agitation has been linked to dementia severity, brain-damaged state, various concomitant psychiatric disorders and frontal lobe dysfunction ${ }^{43-44}$. The involvement of limbic system and associated areas as well as cortical hypometabolism have been suggested to contribute to BPSD. ${ }^{45}$

\subsubsection{Neurotransmitters}

An imbalance of different neurotransmitters (acetylcholine, dopamine, noradrenaline, serotonin, GABA) has been proposed as the neurochemical correlate of BPSD ${ }^{44,46}$ Some evidence suggest that BPSD may result from increased norepinephrine (NE) activity and/or hypersensitive adrenoreceptors compensating for loss of NE neurons with progression $\mathrm{A} \mathrm{D}^{47}$.

Dysregulations in GABA (gamma-aminobutyrate)-ergic, serotonergic and noradrenergic neurotransmitter systems have been associated with increased aggressiveness and disturbances in dementia patients.

AD-related apathy is thought to reflect the interaction between cholinergic deficiency and neuropathological changes in frontal brain regions. ${ }^{48}$

In FTD, increased activity of dopaminergic neurotransmission and altered serotonergic modulation of dopaminergic neurotransmission is associated with agitated and aggressive behavior respectively. ${ }^{45}$ Studies suggest that, neurochemical mechanisms underlying the pathophysiology of BPSD are specific to the type of BPSD and to the type of dementia and hence more targeted pharmacotherapy may be developed in future. ${ }^{49}$

\subsubsection{Genetic Studies}

Genetic studies show that chromosomal abnormalities are a risk factor for the development of BPSD. A relationship between presenilin 1 and psychosis has been demonstrated ${ }^{50}$ but not replicated. An association has also been shown between polymorphism of serotonin receptors genes (5HT102-T/C and 5HTCys23Ser) and visual and auditory hallucinations; with the two polymorphisms having an additive effect on visual hallucinations. ${ }^{51}$ Polymorphism of the dopamine receptors genes is also involved. A genetic polymorphism of the serotonin transporter promoter region (L/L genotype) has been implicated with aggressive behavior in patients with $\mathrm{AD}^{94}$. DRD1, DRD3, SLC6A4 (5HTT) VNTR and 5HTTLPR have been found to be associated with psychosis and aggression/ agitation. ${ }^{52}$

While 5HT2A have been found to be associated with depression, psychosis and aggression/ agitation, 5HT2C have been found to be associated with depression and psychosis but not with aggression/ agitation

APOE E4 been found to be associated with depression and agitation but not with psychosis while COMT has been found to be associated only with psychosis.TPH1 has not been found to be associated with depression, psychosis or aggression in Dementia

\subsection{Care Giver Burden of BPSD}

BPSD occur in a dynamic process involving the patient, the family caregiver and their environment. They are known to be more stressful to caregivers than cognitive or functional decline, because they are most difficult to manage and have a negative impact on the relationships between the caregiver, patient and family. It has been reported that caregivers differ in their emotional responses to BPSD even when facing similar problems and the caregiver's perception of patient's problems is more important than problematic behavior 'per 
se'. Furthermore, caregivers can interpret poorly and react inadequately to BPSD. Caring for dementia sufferers is a highly demanding task both emotionally and physically. Thus, an irritable and sometimes hostile caregiver who easily blames others for the difficulties he/she is experiencing can hardly adapt to a situation of permanent stress such as that of care giving. Furthermore, caregiver personality characteristics may influence the success of intervention programs. Aggressive behavior including physical violence cannot be easily dismissed by caregivers and may make the caregiver fearful of the patient and weaken the caregiver's commitment to ongoing at home care. On the contrary, behaviors that is very difficult to manage, but not directed at the caregiver (e.g., wandering at night), may feel less threatening to the caregiver and result in fewer depressive symptoms ${ }^{54}$. Patient depression is the most frequently reported symptom associated with caregiver depression $(35 \%){ }^{55-60}$ Although sleep disturbances $(18 \%)$ 55, 56, 61, anger/aggression $(12 \%)^{62,63}$, psychosis $(12 \%)^{65,68}$ and agitation $(12 \%){ }^{64,65}$ were also reported by multiple studies. Depression may be especially challenging for caregivers to handle not only because of the difficulty it causes caregivers in dealing with the patients but also because of the negative impact it has on the patient's quality of life. Anger/aggression $(26 \%)^{66,67}$ and depression (17\%) ${ }^{65,66,68,69}$ were the most frequently cited patient symptoms having impact on caregiver burden although sleep disturbances (13\%) ${ }^{70,71}$ and repetitive behavior (13\%) ${ }^{72,73}$ were also reported by multiple studies. Shaji et al reported that delusions, activity disturbances and aggression were perceived by caregivers to be more troublesome at times than memory deficits. Therefore BPSD may be an important factor predicting the caregiver burden in dementia ${ }^{74}$.

\section{Conclusion}

Behavioral and Psychological Symptoms of Dementia are an important clinical issue and need systematic assessment, management and follow up. Often these are the only symptoms for which effective pharmacological and non pharmacological is available as the core symptoms of dementia may not respond to pharmacotherapy in the long run. As BPSD adversely affect quality of life of both patients and caregivers, hence they should be a focus of further comprehensive research.

\section{References}

[1] Colin M, Matilde L. Global burden of dementia in the year 2000: summary of methods and data sources. 2000. Global Burden of Diseases 2000. Dialogues Clin Neurosci. Jun 2009; 11(2): 217-228.

[2] Brodaty H and Donkin M. Family Caregivers of people with dementia. Dialogues Clin Neurosci. Jun 2009; 11(2): 217 228.Family caregivers of people with dementia

[3] WHO. Active aging: A policy framework. 2002 health report.
Geneva.Geneva: World Health Organization; 2002.

[4] Mathers C, Matilde Leonardi. Global burden of dementia in the year 2000 .Summary of methods and data sources. World Health Organization Das SK, Pal S, Ghosal MK: Dementia: Indian scenario; Neurology India Nov-Dec 2012; 60(6): 618.

[5] Ferri CP, Prince M, Brayne C, Brodaty C, Fratiglioni L, Ganguli M,et al. Global prevalence of dementia: A Delphi consensus study. Lancet 2005;366: 2112-7.

[6] Lyketsos CG SM, Tschanz JT, Norton MC, Steffens DC, Breitner JC. Mental and behavioral disturbances in dementia: Findings from the Cache County Study on Memory in Aging. Am J Psychiatry. 2000; 157(5):708-714.

[7] Burns A, Jacoby, R. and Levy, R. (1990) Psychiatric phenomena in Alzheimer's disease. I: Disorders of thought content. British Journal of Psychiatry, 157, 72-76.

[8] Australian Medicines Handbook. Australian Medicines Handbook Drug Choice Companion: Aged Care. 2nd ed: Adelaide: Australian Medicines Handbook; 2006.

[9] Pinto C and Seethalakshmi R. Behavioral and psychological symptoms of dementia in an Indian population: comparison between Alzheimer's disease and vascular dementia. International Psychogeriatrics (2006), 18:1, 87-93.

[10] Byrne GJ. Pharmacological treatment of behavioural problems in dementia. Australian Prescriber.2005; 28 :67-70.

[11] Hersch EC, Falzgraf S. Management of the behavioral and psychological symptoms of dementia. Clinical Interventions in Aging 2007;2(4):611-621.

[12] International Psycho geriatric Association. (2012) IPA BPSD Specialists Guide Online. http://www.bsa.ualberta.ca/sites/default/files/__IPA_BPSD Specialists_Guide_Online.pdf. Accessed 4 December 2014.

[13] Cummings JL. The Neuropsychiatric Inventory- Assessing psychopathology in dementia patients. Neurology May 1997 vol. 48 no. 5 Suppl 6 10S-16S

[14] Ballard C, Waite J, Birks J. 2006. Atypical antipsychotics for aggression and psychosis in Alzheimer'sDisease. Cochrane Database of Systematic Reviews, (1):CD003476.

[15] Paulsen J, Salmon D, Thal L, et al. 2000. Incidence of and risk factors for hallucinations and delusions in patients with probable AD. Neurology, 54:1965-71.

[16] World Health Organization (1993). The ICD-10 classification of mental and behavioural disorders: Diagnostic criteria for research. Geneva, Switzerland: World Health Organization.

[17] American Psychiatric Association. Diagnostic and Statistical Manual of Mental Disorders (DSM-5). Arlington, VA: American Psychiatric Association; 2013.

[18] Lawlor BA. Behavioral and psychological symptoms in dementia: the role of atypical antipsychotics. The Journal of Clinical Psychiatry. 2004; 65 Suppl 11:5-10.

[19] Ballard C, Howard R. Neuroleptic drugs in dementia: benefits and harm. Nature Reviews Neuroscience. Jun 2006;7(6):492500 .

[20] Kar N. Behavioral and psychological symptoms of dementia and their management.Indian J Psychiatry. 2009 Jan;51 Suppl 1:S77-86. 
[21] Zaudig M. 2000. A risk-benefit assessment of risperidone for the treatment of behavioral and psychological symptoms in dementia. Drug Safety, 23:183-95.

[22] Jost BC, Grossberg GT. The evolution of psychiatric symptoms in Alzheimer's disease: a natural history study.J. Am. Geriatr. Soc. 1996; 44:1078-1081.

[23] Borroni B, Agosti C, Padovani A. Behavioral and psychological symptoms in dementia with Lewy-bodies (DLB): frequency and relationship with disease severity and motor impairment. Arch Gerontol Geriatr 2008;46:101-6.

[24] Cummings, J. L., Miller, B., Hill, M. A. and Neshkes, R. (1987). Neuropsychiatric aspects of multi-infarct dementia and dementia of the Alzheimer type. Archives of Neurology, 44, 389-393.

[25] Shaji S, Promodu K, Abraham T, Roy KJ, Verghese A. An epidemiological study of dementia in a rural community of Kerala, India, Br J Psychiatry 1996; 168:745-9.

[26] Tripathi M, Vibha D. Review An approach to and the rationale for the pharmacological management of behavioral and psychological symptoms of dementia: Ann Indian Acad Neurol 2010; 13:S94-8.

[27] Berrios, G. E. and Brook, P. Delusions and the psychopathology of the elderly with dementia. Acta Psychiatrica Scandinavica, 1985; 72, 296-301.

[28] .Swearer J. Behavioral disturbances in dementia. In: Morris JC editor. Handbook of dementing illnesses. New York: Marcel Decker Inc.; 1994.

[29] McKeith I, Fairbairn A, Perry R, Thompson P, Perry E. Neuroleptic sensitivity in patients with senile dementia of the Lewy body type. BMJ 1992; 305:673-8.

[30] Jeste, D. and Finkel, S. Psychosis of Alzheimer's disease and related dementias.Diagnostic criteria for a distinct syndrome. American Journal of Geriatric Psychiatry, 2000; 146, 577-587.

[31] Cook, S.E., Miyahara, S., Bacanu, S.A., Perez-Madrinan, G., Lopez, O.L., Kaufer, D.I., Nimgaonkar, V.L., Wisniewski, S.R., DeKosky, S.T., Sweet, R.A., 2003. Psychotic symptoms in Alzheimer disease: evidence for subtypes. Am. J. Geriatr. Psychiatry 11, 406-413.

[32] Schreinzer D, Ballaban T, Brannath W, Lang T, et al. (2005). Components of behavioral pathology in dementia. International Journal of Geriatric Psychiatry 20(2):137-45.

[33] Perez-Madrinan G, Cook SE, Saxton JA et al. Alzheimer disease with psychosis: excess cognitive impairment is restricted to the misidentification subtype. Am J Geriatr Psychiatry 2004; 12 (5): 449-456.

[34] Reisberg B, Borenstein J, Salob SP, Ferris SH, Franssen E, Georgotas A. Behavioural symptoms in Alzheimer's disease: Phenomenology and treatment. J Clin Psychiatry 1987;48:915 .

[35] Wragg, R. E. and Jeste, D. V. Overview of depression and psychosis in Alzheimer's dementia. American Journal of Psychiatry, 1989; 146, 577-587.

[36] Devanand, D. et al. Depressed mood and the incidence of Alzheimer's disease in the elderly living in the community. Archives of General Psychiatry, 1996; 53, 175-182.
[37] Pinto, C., Panikker, D., Deshpande, N. and Vas, C. J. Behavioral disturbances in dementia. Journal of the Association of Physicians of India, 2000; 48, 386-389

[38] Amoo G, Akinyemi RO, Onofa LU, Akinyemi JO; Profile of clinically-diagnosed dementias in a neuropsychiatric practice in Abeokuta, South-Western Nigeria;African Journal of Psychiatry• November 2011;14:377-8.

[39] Farber, N.B., Rubin, E.H., Newcomer, J.W., Kinscherf, D.A., Miller, J.P., Morris, J.C., Olney, J.W., McKeel, D.W. Jr. Increased neocortical neurofibrillary tangle density in subjects with Alzheimer disease and psychosis. Arch. Gen. Psychiatry, 2009; 57, 1165-1173.

[40] Lopez, O.L., Smith, G., Becker, J.T., Meltzer, C.C., DeKosky, S.T. The psychotic phenomenon in probable Alzheimer's disease: a positron emission tomography study. J. Neuropsychiat. Clin.Neurosci., 2001; 13, 50-55.

[41] Sultzer, D.L., Brown, C.V., Mandelkern, M.A., Mahler, M.E., Mendez, M.F., Chen, S.T., Cummings, J.L. Delusional thoughts and regional frontal/temporal cortex metabolism in Alz-heimer's disease. Am. J. Psychiatry, 2003; 160, 341-349.

[42] Senanarong V, Cummings JL, Fairbanks L, Mega M, Masterman DM, O'Connor SM, et al. Agitation in Alzheimer's disease is a manifestation of frontal lobe dysfunction. Dement Geriatr Cogn Disord 2004; 17:14-20.

[43] Boyle PA,Malloy PF. Treating apathy in Alzheimer's disease. Dement Geriatr Cogn Disord 2004; 17:91-9.

[44] Engelborghs S, Vloeberghs E, Le Bastard N, Van Buggenhout $\mathrm{M}$, Mariën $\mathrm{P}$, Somers $\mathrm{N}$, et al. The dopaminergic neurotransmitter system is associated with aggression and agitation in frontotemporal dementia. Neurochem Int 2008; 52:1052-60.

[45] Parnetti L, Amici S, Lanari A, Gallai V. Pharmacological treatment of non-cognitive disturbances in dementia disorders. Mech Ageing Dev 2001; 122:2063-9.

[46] Ganguli M, Dodge HH, Shen C, Pandav RS, DeKosky ST. Alzheimer disease and mortality: A 15-year epidemiological study. Archives of Neurology, 2005: 62 (5) 779- 784.

[47] Mckhann G, Drachmann D, Folstein M etal.clinical diagnosis of Alzheimer's disease;report of NINCDS-ADRDA work group under the auspices of Department of health and Human services task forces on Alzheimer's disease. Neurology 1984; 34(7):939-44.

[48] Galton CJ, Patterson K, Xuereb JH, et al, Atypical and Typical Presentation of Alzheimer's disease; a clinical neuropsychological, neuroimaging and pathological study of 13 cases. Brain2000; 123(pt 3):484-98.

[49] Harvey, R.J., Ellison, D., Hardy, J., Hutton, M., Roques, P.K., Collinge, J., Fox, N.C., Rossor, M.N. Chromosome 14 familial Alzheimer's disease: the clinical and neuropathological characteristics of a family with a leucine-serine (L250S) substitution at codon 250 of the presenilin lágene. J. Neurol. Neurosurg. Psychiatry, 1998; 64, 44-49.

[50] Holmes, C., Arranz, M.J., Powell, J.F., Collier, D.A., Lovestone, S. 5-HT2A and 5- HT2C receptor polymorphisms and psychopa-thology in late onset Alzheimer's disease. Hum. Mol. Genet., 1998; 7, 1507-1509. 
[51] Sukonick, D.L., Pollock, B.G., Sweet, R.A., Mulsant, B.H., Rosen, J., Klunk, W.E., Kastango, K.B., DeKosky, S.T., Ferrell, R.E. The 5-HTTPR*S/*L Polymorphism and Aggressive Behav-ior in Alzheimer Disease. Arch. Neurol., 58, $2001 ; 1425-1428$.

[52] Ballard CG1, Gauthier S, Cummings JL, Brodaty $\mathrm{H}$, Grossberg GT, Robert P, Lyketsos CG. Management of agitation and aggression associated with Alzheimer disease. Nat Rev Neurol. 2009 May; 5(5):245-55.

[53] Katherine Ornstein, Ph.D., M.P.H., Joseph E. Gaugler, Ph.D., D.P. Devanand, M.D.,Nikos Scarmeas, M.D., Carolyn Zhu, Ph.D., Yaakov Stern, Ph.D. The Differential Impact of Unique Behavioral and Psychological Symptoms for the Dementia Caregiver: How and Why Do Patients' Individual Symptom Clusters Impact Caregiver Depressive Symptoms? Am J. Geriatr Psychiatry 00:00, 2012:1-12.

[54] Donaldson C, Tarrier N, Burns A. Determinants of carer stress in Alzheimer's disease. International Journal of Geriatric Psychiatry $1998,13(4): 248-256$.

[55] LoGiudice D, Waltrowicz W, McKenzie S, Ames D, Flicker L. Prevalence of dementia among patients referred to an aged care assessment team and associated stress in their carers. Aust J Public Health 1995 Jun; 19(3):275-279.

[56] Heok KE, Li TS. Stress of caregivers of dementia patients in the Singapore Chinese family. International Journal of Geriatric Psychiatry 1997; 12(4):466-469.

[57] Harwood DG, Barker WW, Cantillon M, Loewenstein DA, Ownby R, Duara R. Depressive symptomatology in firstdegree family caregivers of Alzheimer disease patients: a cross-ethnic comparison. Alzheimer Dis Assoc Disord 1998 Dec; 12(4):340-346.

[58] Brodaty H, Luscombe G. Psychological morbidity in caregivers is associated with depression in patients with dementia. Alzheimer Dis Assoc Disord 1998 Jun; 12(2):62- 70

[59] Neundorfer MM, McClendon MJ, Smyth KA, Stuckey JC, Strauss ME, Patterson MB. A longitudinal study of the relationship between levels of depression among persons with Alzheimer's disease and levels of depression among their family caregivers. J Gerontol B Psychol Sci Soc Sci 2001 Sep; 56(5):301-313.

[60] Berger G, Bernhardt T, Weimer E, Peters J, Kratzsch T, Frolich L. Longitudinal study on the relationship between symptomatology of dementia and levels of subjective burden and depression among family caregivers in memory clinic patients. Journal of Geriatric Psychiatry \& Neurology 2005 Sep; 18(3):119-128.
[61] Covinsky KE, Newcomer R, Fox P, et al. Patient and caregiver characteristics associated with depression in caregivers of patients with dementia. J Gen Intern Med 2003 Dec;18(12):1006-1014.

[62] Danhauer SC, McCann JJ, Gilley DW, Beckett LA, Bienias JL, Evans DA. Do behavioral disturbances in persons with Alzheimer's disease predict caregiver depression over time? Psychol Aging 2004 Mar; 19(1):198-202.

[63] Victoroff J, Mack WJ, Nielson KA. Psychiatric complications of dementia: impact on caregivers. Dement Geriatr Cogn Disord 1998 Jan; 9(1):50-55.

[64] Asada T, Kinoshita T, Kakuma T. Analysis of behavioral disturbances among community-dwelling elderly with Alzheimer disease. Alzheimer Dis Assoc Disord2000 Jul; 14(3):160-167.

[65] Woods B, Thorgrimsen L, Spector A, et al: Improved quality of life and cognitive stimulation therapy in dementia. Aging Ment Health 2006; 10(3):219-226.

[66] Hoe J, Hancock G, Livingston G, et al: Quality of life of people with dementia in residential care homes. $\mathrm{Br} \mathrm{J}$ Psychiatry 2006; 188:460-464.

[67] Magai C, Cohen CI. Attachment style and emotion regulation in dementia patients and their relation to caregiver burden. $\mathrm{J}$ Gerontol B Psychol Sci Soc Sci 1998 May; 53(3):147-154.

[68] Onishi J, Suzuki Y, Umegaki H, Nakamura A, Endo H, Iguchi A. Influence of behavioral and psychological symptoms of dementia (BPSD) and environment of care on caregivers' burden. Arch Gerontol Geriatr 2005 Sep; 41(2):159-168.

[69] Allegri RF, Sarasola D, Serrano CM, et al. Neuropsychiatric symptoms as a predictor of caregiver burden in Alzheimer's disease. \&europsychiatr Dis Treat 2006 Mar; 2(1):105-110.

[70] Grafstrom M, Winblad B. Family burden in the care of the demented and nondemented elderly--a longitudinal study. Alzheimer Dis Assoc Disord 1995; 9(2):78-86.

[71] Bedard M, Kuzik R, Chambers L, Molloy DW, Dubois S, Lever JA. Understanding burden differences between men and women caregivers: the contribution of carerecipient problem behaviors. Int Psychogeriatr 2005 Mar; 17(1):99-118.

[72] Lim PPJ, Sahadevan S, Choo GK, Anthony P. Burden of caregiving in mild to moderate dementia: An Asian experience. International Psychogeriatrics 1999 Dec; Vol. 11(4):411-420.

[73] Emmatty LM, Bhatti RS, Mukalel. The experience of burden in India: A study of dementia caregivers. Dementia 2006; 5:223-32. 